\title{
Antimicrobial Potential of Natural and Semi-Synthetic ent-Kaurane and ent-Pimarane Diterpenes against Clinically Isolated Gram-Positive Multidrug-Resistant Bacteria
}

\author{
Ana Carolina F. Soares, ${ }^{a}$ Priscilla M. Matos, ${ }^{a}$ Karime F. da Silva, ${ }^{a}$ Carlos H. G. Martins, ${ }^{a}$ \\ Rodrigo C. S. Veneziani, ${ }^{\circledR a}$ Sérgio R. Ambrósio, ${ }^{a}$ Herbert J. Dias, ${ }^{b}$ Raquel A. dos Santos ${ }^{a}$ \\ and Vladimir C. G. Heleno ${ }^{\circledR} * a$ \\ ${ }^{a}$ Núcleo de Pesquisa em Ciências Exatas e Tecnológicas, Universidade de Franca, \\ 14404-600 Franca-SP, Brazil \\ ${ }^{b}$ Departamento de Química, Faculdade de Filosofia, Ciências e Letras de Ribeirão Preto (FFCLRP), \\ Universidade de São Paulo, 14040-900 Ribeirão Preto-SP, Brazil
}

\begin{abstract}
In this work, a search for antimicrobial agents against multi-drug resistant (MDR) bacteria was undertaken. It involved two natural diterpenes of different basic skeletons, named ent-kaurenoic acid and ent-pimaradienoic acid, that were used as precursors to access 28 semi-synthetic derivatives that were also submitted to biological assays. All 30 substances were assayed against a set of seven clinically isolated MDR bacteria, including three Staphylococcus aureus strains. Results classified both natural compounds as promising bactericidal antimicrobial agents against these MDR bacteria, especially for their performance in time-kill curve assay, improving on the positive control vancomycin. Moreover, di-hydro ent-pimaradienoic acid, obtained as one of the derivatives, also displayed promising minimum inhibitory concentration (MIC) values against the microorganism set, proving optimum activity against $S$. aureus strains. Thereby, this work also yielded a promising semi-synthetic bacteriostatic antimicrobial agent against MDR S. aureus. Furthermore, the study was carried out with 30 structures in order to verify the veracity and scope of Urzúa's hypothesis about the structure-activity relationship between diterpenes and antimicrobial action. Our results are $93 \%$ in agreement with this hypothesis.
\end{abstract}

Keywords: kaurane diterpenes, pimarane diterpenes, Staphylococcus aureus, multidrugresistant bacteria, antimicrobial activity

\section{Introduction}

Infectious diseases caused by bacteria are widespread in the world and constitute a public health problem in several countries. ${ }^{1-3}$ For some decades, one can note a severe decrease in drug's efficacy due to the increase of bacterial resistance as well as the emergence of new infectious pathologies. This highlights the need for new agents to fight these pathogenic bacteria. ${ }^{4}$

The emergence of multi-drug resistant (MDR) microorganisms has become a major concern for global health because it considerably increases the mortality rate of patients in comparison to the same non-resistant pathogen. Moreover, the resistance occurs by rampant acceleration in the transformation of these bacteria. ${ }^{3,5}$

*e-mail: vladimir.heleno@unifran.edu.br
According to the World Health Organization (WHO), ${ }^{2}$ Staphylococcus aureus is one of the most important species from some selected bacteria, which are resistant to antibacterial agents and are considered as international concern. These bacteria are resistant to: methicillin (methicillin-resistant: Staphylococcus aureus (MRSA), S. epidermidis (MRSE), S. haemolyticus (MRSH), S. capitis (MRSC)), vancomycin (vancomycin intermediate resistant $S$. aureus (VISA), S. capitis (VISC), Enterococcus (E. faecalis and E. faecium) (VRE)), penicillin (penicillin nonsusceptible Streptococcus pneumoniae (PNSSP)), among others., ${ }^{2,6,7}$

Due to MDR, these microorganisms are responsible for causing serious infections both in hospitals or communities, covering respiratory, urinary and intestinal infections as well as pneumoniae, toxic shock syndrome and septicemia. The condition of MDR of these microorganisms to 
antibiotics, considering high medical expenses and prolonged hospitalization of patients, ${ }^{8-10}$ considerably increases the risk of mortality. Therefore, the search for new lead compounds became urgent and very important to provide solutions or attempts against this global health problem. ${ }^{4}$

The use of natural products (NP) in the search for biological active compounds can be considered as a promising source of new drugs. ${ }^{4,11}$ Their remarkable potential, proven by the quantity of papers that describe considerable number of new bioactive compounds every year, ${ }^{11,12}$ should not be ignored. In addition, a semi-synthetic approach can be adopted and provide even more active compounds of interest. ${ }^{11}$

Diterpenes are one of the most important classes of NP, due to their wide range of biological and ecological activities, such as antimicrobial, ${ }^{13}$ cytotoxicity with relative selectivity for cancer cells, ${ }_{14}^{14}$ antiparasitic, ${ }^{15}$ anti-HIV activity, ${ }^{16}$ anti-inflammatory, ${ }^{17}$ among others. In particular, two diterpene skeletons could be highlighted in this class: kauranes ${ }^{18,19}$ and pimaranes. ${ }^{13,20}$

Moreover, one can observe that compounds with slight structural differences show very different biological activities in several cases. ${ }^{21-24}$ It must also be considered that these natural substances may be submitted to chemical modification by chemical reactions or biotransformation providing analogues that may be even more active. ${ }^{23,24}$ Due to that, this is an interesting way to obtain new active compounds, which is important in searching for new antibiotics and treatments aiming to overcome microbial resistance.

As part of our research interests about the evaluation of biological activities of diterpenes, ${ }^{21,23}$ considering the semisynthesis approach ${ }^{24,25}$ and some interesting previous results obtained in our research group,$^{13}$ we decided to perform a search for active compounds against MDR bacteria in two strands: (i) to search among natural diterpenes that could be promising skeletons due to their previous results in other activities; (ii) to modify the original structures to search for active semi-synthetic derivatives. Chosen structures were the natural diterpenes ent-kaurenoic acid (1) and ent-pimaradienoic acid (2) (Figure 1). Both substances are the major components in each one's botanical source: Mikania glomerata Sprengel (Asteraceae) for ent-kaurenoic acid and Viguiera arenaria (Asteraceae) for ent-pimaradienoic acid.

We herein present our research results on submitting the natural substances to structural modifications, such as hydrogenation, methoxylation and esterification. Antimicrobial activities of natural and semi-synthetic substances against some multiresistant microorganisms including Staphylococcus aureus were evaluated.

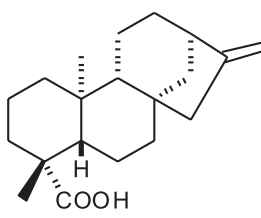

1

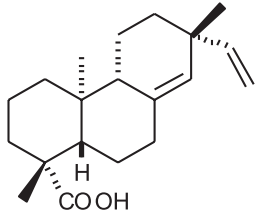

Figure 1. Biologically active diterpenes ent-kaurenoic acid (1) and ent-pimaradienoic acid (2).

\section{Experimental}

\author{
General
}

Nuclear magnetic resonance (NMR) spectra were recorded on a Bruker Avance DRX 400 spectrometer (Karlsruhe, Germany) (400 MHz for ${ }^{1} \mathrm{H}$ and $100 \mathrm{MHz}$ for $\left.{ }^{13} \mathrm{C}\right)$. Samples were dissolved in $\mathrm{CDCl}_{3}$ with tetramethylsilane (TMS), used as internal reference. The chemical shifts values are given in $\mathrm{ppm}$. Structural modification procedures were performed according to protocols referenced below. Thin layer chromatography (TLC) was conducted using pre-coated silica gel plates for TLC (Merck, art. 107730, Darmstadt, Germany). Vacuum liquid chromatography (VLC) was carried out using silica gel 60H (Merck, art. 7736 , Darmstadt, Germany) in glass columns with $5-10 \mathrm{~cm}$ i.d. Classic column was accomplished with silica gel 60 (Merck, art. 9385, Darmstadt, Germany) in a 450-25 mm glass column.

Plant material (compound $\mathbf{1}$ )

The certified dried and powdered aerial parts of M. glomerata were purchased from the Brazilian company Nutri Comércio de Ervas Ltda, based on the city of São Paulo-SP.

\section{Isolation of compound $\mathbf{1}$}

Firstly, a dichloromethane (DCM) crude extract from M. glomerata was obtained and then ent-16-kauren-19-oic acid (1) was purified from this extract as described in our previous work. ${ }^{23}$

\section{Isolation of compound 2}

An aliquot $(24.0 \mathrm{~g})$ of the dichloromethane root crude extract from $V$. arenaria, previously obtained in our research group, ${ }^{26}$ was suspended in a $\mathrm{MeOH} / \mathrm{H}_{2} \mathrm{O}$ solution $(9: 1 \mathrm{v} / \mathrm{v})$ and partitioned with $n$-hexane and DCM. The DCM extract ( $3.0 \mathrm{~g}$ ) was refractioned using several chromatographic techniques, such as vacuum liquid chromatography, flash chromatography and preparative 
thin layer chromatography, as well as recrystallization with methanol, as previously described.$^{26}$ These procedures furnished $0.6 \mathrm{~g}$ of ent-pimara-8(14),15-dien-19-oic acid (2).

Semi-synthetic derivatives

\section{Hydrogenation reactions}

About $300.0 \mathrm{mg}$ of each compound, $\mathbf{1}$ and $\mathbf{2}$, were submitted to catalytic hydrogenation reaction in a stainless-steel pressure vessel equipped with magnetic stirrer. The substrates were dissolved in absolute ethanol (Tedia, Fairfield, USA), and after addition of catalyst $\mathrm{Pd} / \mathrm{C}$ (5\%, Aldrich, Steinheim, Germany), the reactor was purged three times and pressurized with hydrogen (4 atm). The mixture was stirred at room temperature for $2 \mathrm{~h}$ and the catalyst was filtered off. ${ }^{24}$ These procedures furnished the derivatives $\mathbf{8}$ and $\mathbf{2 5}$ in quantitative yield.

\section{Methoxy-group addition reaction}

A sample of $300.0 \mathrm{mg}$ of $\mathbf{1}$ was dissolved in $12 \mathrm{~mL}$ of methanol and twelve drops of concentrated sulfuric acid were added to this reaction mixture. This mixture was stirred for $18 \mathrm{~h}$ at room temperature to furnish derivative $\mathbf{1 4}$ also in quantitative yield. ${ }^{27}$

\section{Esterification reactions}

This kind of structural modification led to most derivatives used in this work. Five compounds, named 1, 8, 14, 2 and 25 were submitted to esterification reactions with five aryl and alkyl halides, following the procedure previously described in the literature..$^{27,28}$ The derivatives obtained from each halide, respectively, were: bromobutane $(\mathbf{3}, \mathbf{9}, \mathbf{1 5}, \mathbf{2 0}, \mathbf{2 6})$, benzyl bromide $(\mathbf{4}, \mathbf{1 0}, \mathbf{1 6}, \mathbf{2 1}, \mathbf{2 7})$, 4-chlorobenzyl bromide $(5,11,17,22,28)$, 4-bromobenzyl bromide $(6,12,18,23$, 29) and iodomethane $(7,13,19,24,30)$.

\section{Purification of isolated and synthetized compounds}

The isolated substances and their semi-synthetic derivatives were purified through classic chromatography filled with silica gel 60 and $60 \mathrm{H}(1: 1)$ and eluted with a mixture of $n$-hexane and ethyl acetate $(8: 2 \mathrm{v} / \mathrm{v})$.

\section{Microorganisms}

The assayed MDR bacteria strains were kindly supplied by Hospital das Clínicas de Ribeirão Preto (HCRP), Ribeirão Preto City, São Paulo State, Brazil: Staphylococcus aureus (180 HCRP), Staphylococcus aureus (222 HCRP), Staphylococcus aureus (223 HCRP), Staphylococcus capitis (207 HCRP), Staphylococcus epidermidis (177 HCRP),
Staphylococcus haemolyticus (213 HCRP) and Enterococcus faecalis (179 HCRP).

Bacterial strains and antimicrobial testing

The minimal inhibitory concentration values (MIC, lowest concentration of the compound capable of inhibiting microorganism growth) and the minimal bactericidal concentration (MBC, lowest concentration of the compound at which $99.99 \%$ or more of the initial inoculum was killed) were determined in triplicate by using the microdilution broth method in 96-well microplates.

Samples were dissolved in dimethyl sulfoxide (DMSO; Synth, Diadema, Brazil) at $1 \mathrm{mg} \mathrm{mL}^{-1}$, followed by dilution in tryptic soy broth (Difco, Detroit, USA); concentrations ranging from 400.0 to $0.195 \mu \mathrm{g} \mathrm{mL} \mathrm{m}^{-1}$ were achieved. The final DMSO content was $5 \%(\mathrm{v} / \mathrm{v})$ and this solution was used as negative control. The inoculum was adjusted for each organism, to yield a cell concentration of $5 \times 10^{5}$ colony forming units (CFU) per $\mathrm{mL}$, according to previous standardization by the Clinical and Laboratory Standards Institute. ${ }^{29}$ One inoculated well was included to allow control of the adequacy of the broth for organism growth. One non-inoculated well, free of antimicrobial agent, was also employed, to ensure medium sterility. Vancomycin (VAN) was used as positive control. The microplates (96-wells) were sealed with plastic film and incubated at $37{ }^{\circ} \mathrm{C}$ for $24 \mathrm{~h}$. After that, resazurin $(30 \mu \mathrm{L})$ in aqueous solution $(0.02 \%)$ was added to the microplates and incubated again for $15 \mathrm{~min}$ at $37^{\circ} \mathrm{C}$, to indicate microorganism viability..$^{30,31}$

Before the addition of resazurin and in order to determine $\mathrm{MBC}$, an aliquot of the inoculum was aseptically removed from each well presenting no apparent growth and then plated onto tryptic soy agar supplemented with $5 \%$ sheep blood. The plates were incubated as previously described. Determination of the MBC values was only performed for the most active compounds (1, 2 and 25), against one of the evaluated strains of Staphylococcus aureus (180 HCRP), which has been considered the major hospital-acquired pathogen. ${ }^{32}$

Time-kill curves

Time-kill assays against Staphylococcus aureus (180 HCRP) using the compounds 1, 2 and 25, the only ones which exhibited the higher antimicrobial activities, were conducted in triplicate as described in the literature. ${ }^{33}$

Tubes containing $\mathbf{1}, \mathbf{2}$ and $\mathbf{2 5}$ at final concentrations of $6.25,6.25$ and $50.0 \mu \mathrm{g} \mathrm{mL}-1$, respectively (one, two, and three-times the MBC of 1, 2 and 25 for $S$. aureus, respectively) were inoculated with the tested microorganism, resulting in a start bacterial density of 
$5 \times 10^{5} \mathrm{CFU} \mathrm{mL}{ }^{-1}$, and then incubated at $37^{\circ} \mathrm{C}$. Samples were removed for determination of viable strains at 0,6 , 12 and $24 \mathrm{~h}$ after incubation, followed by dilution, when necessary, in sterile fresh medium. The diluted samples $(50 \mu \mathrm{L})$ were spread onto tryptic soy agar, incubated at $37{ }^{\circ} \mathrm{C}$ and counted after $48 \mathrm{~h}$. Time-kill curves were constructed by plotting the $\log _{10} \mathrm{CFU} \mathrm{mL}^{-1}$ versus time. The assays were performed in triplicate for each concentration and also for the positive (vancomycin, VAN, $1.475 \mu \mathrm{g} \mathrm{mL}^{-1}$ ) and negative controls (inoculum, $3.16 \times 10^{5}$ ). VAN was used at its $\operatorname{MBC}\left(0.7375 \mu \mathrm{g} \mathrm{mL}^{-1}\right)$.

\section{Cytotoxicity assay}

To assess the effect of $\mathbf{1 , 2}$ and $\mathbf{2 5}$ on cell viability of primary human fibroblast (GM 07492-A, Coriell Cell Repositories, New Jersey, USA) the XTT colorimetric assay was performed. Briefly, cells were trypsinized and seeded in 96-well plate at a concentration of $5 \times 10^{4}$ cells per well in DMEM + HAM-F10 (1:1, v/v) medium (Sigma, St. Louis, USA) supplemented with $10 \%$ of fetal bovine serum (Life Technologies, California, USA). After $24 \mathrm{~h}$ of incubation at $37{ }^{\circ} \mathrm{C}$, cell cultures were treated with different concentrations of $\mathbf{1}, \mathbf{2}$ and $\mathbf{2 5}$ dissolved in DMSO $(1 \%, \mathrm{v} / \mathrm{v})$ ranging from 7.8 to $500.0 \mu \mathrm{M}$ for another $24 \mathrm{~h}$. Cell viability was assessed with the Cell Proliferation Kit II (Roche, Mannhein, Germany) according to the manufacturer's instructions. The absorbance of the orange formazan product was detected at $490 \mathrm{~nm}$ with the reference wavelength at $620 \mathrm{~nm}$ in a microplate reader Sunrise (Tecam, Männdorf, Switzerland). Cell viability was expressed as the percentage of the negative control. Doxorubicin at $3.0 \mu \mathrm{g} \mathrm{mL} \mathrm{m}^{-1}$ was used as the positive control.

\section{Results and Discussion}

The isolation procedures of compounds $\mathbf{1}$ and $\mathbf{2}$ yielded enough material in high purity to perform chemical transformations. Both compounds were identified by NMR methods, through comparison with literature data, as both natural compounds are widely known. The data is in alignment with the literature: Mota et al. ${ }^{27}$ for compound $\mathbf{1}$ and Porto et al. ${ }^{31}$ for $\mathbf{2}$.

Semi-synthetic hydrogenated derivatives (8 and 25) had their structure confirmed by NMR data and also by comparison with previously reported data in the literature: Tincusi et al. ${ }^{34}$ for $\mathbf{8}$ and Kumata et al. ${ }^{35}$ for $\mathbf{2 5}$. Both structures are easily confirmed due to the small difference between them and their precursors. For the case of the semi-synthetic methoxylated derivative (14) there is also a set of data reported previously in the literature, ${ }^{27}$ to which our experimental data were compared to. The comparison revealed enough agreement to confirm the structure. The ${ }^{1} \mathrm{H}$ and ${ }^{13} \mathrm{C}$ NMR data for all compounds $(\mathbf{1}, \mathbf{2}, \mathbf{8}, 14$ and 25$)$ are also in perfect agreement to each structure.

Regarding the ester derivatives (3-7, 9-13, 15-24 and 26-30), obtained from the esterification reactions applied to compounds $1,2,8,14$ and 25 , all NMR data structural assignments were performed through the same methodology. All spectra were compared to each acid precursor's spectra with special attention to the signals from the new chain now linked to the carboxyl oxygen. Much of this was already done before and published by our research group. ${ }^{27}$ Due to this, it was not difficult to confirm all structures. Moreover, some NMR data were also compared to previously published data in the literature, such as: 3-7, ${ }^{27,28} 13^{27}$ and 19. ${ }^{27}$ NMR spectral data for all compounds ( $\mathbf{1}$ to $\mathbf{3 0}$ ) can be found in Supplementary Information section.

After careful purification by classic chromatography as described, all substances showed high purity grade, determined to be in a range from 95 to $99 \%$ by NMR. As the adequate purity was certified, each compound (1 to 30) could then be submitted to the antimicrobial assays. Table 1 comprises all most relevant experimental results for biological assays in this work. Compounds 3-19, 21-24,

Table 1. In vitro antimicrobial activity of $\mathbf{1 , 2}$ and some of their derivatives

\begin{tabular}{|c|c|c|c|c|c|c|c|c|}
\hline \multirow{2}{*}{ Microorganism } & \multicolumn{8}{|c|}{ Minimum inhibitory concentration $(\mathrm{MIC}) /\left(\mu \mathrm{g} \mathrm{mL} \mathrm{m}^{-1}\right)$} \\
\hline & VAN & 1 & 2 & 20 & 25 & 26 & 27 & 28 \\
\hline S. aureus (180 HCRP) & 0.7375 & 12.5 & 6.25 & a & 6.25 & 400 & 200 & 400 \\
\hline S. aureus (222 HCRP) & 0.7375 & 12.5 & 6.25 & a & 6.25 & a & a & a \\
\hline S. aureus (223 HCRP) & 0.7375 & 12.5 & 400 & a & 6.25 & a & a & a \\
\hline S. capitis (207 HCRP) & 0.7375 & 12.5 & 6.25 & a & 6.25 & 400 & a & a \\
\hline S. epidermidis (177 HCRP) & 1.475 & 25 & 12.5 & 400 & 400 & 400 & 400 & 400 \\
\hline S. haemolyticus (213 HCRP) & 0.7375 & 12.5 & 6.25 & a & a & 400 & a & a \\
\hline E. faecalis (179 HCRP) & 0.3688 & 12.5 & 6.25 & a & a & a & a & a \\
\hline
\end{tabular}

${ }^{a} \mathrm{MIC}$ values higher than $400.0 \mu \mathrm{g} \mathrm{mL}{ }^{-1}$; positive control: vancomycin hydrochloride (VAN); negative control (5\% DMSO solution) did not affect microorganism growth. 
29 and 30 showed MIC over $400 \mu \mathrm{g} \mathrm{mL}^{-1}$ for all assayed microorganisms, classifying them as not active against those multi-resistant strains. ${ }^{36}$

Different modes of action have been demonstrated by antimicrobial compounds. ${ }^{37}$ Although diterpenes have been considered an important class of plant metabolites for the search of new substances with promising biological potential by some authors, including antimicrobial, their action mechanisms in this activity are not fully understood. ${ }^{38}$ The suggestion by Urzúa et al. ${ }^{38}$ is that these metabolites promote bacterial lysis through their insertion into the lipophilic cell membrane, inducing subsequent disruption of the lipophilic cell membrane. According to these authors, the structural features that promote the efficient antibacterial activity include a lipophilic structure, capable of insertion into the cell membrane, and just one strategically positioned hydrogenbond-donor group (HBD; hydrophilic group), which interacts with the phosphorylated groups on the membrane.

Our first effort in the search for active compounds against these MDR microorganisms was to evaluate the natural ones. In a previously published work from our research group, ${ }^{13}$ carried out with pimarane diterpenes, the best and promising results were assigned to substances with one $\mathrm{OH}$ group bonded to the hydrocarbon basic diterpene structure. The natural substance at that occasion was a hydrocarbon and it was defined as inactive against the assayed microorganisms. Moreover, the assayed substances with two $\mathrm{OH}$ groups or with one $\mathrm{OH}$ group and a $\mathrm{C}=\mathrm{O}$ were also stated as inactive by their results. This perfectly meets Urzúa's hypothesis about HBD groups and antimicrobial activity ${ }^{38}$ Due to this, it was decided to assay ent-pimaradienoic acid (2) herein to find out if the HBD hypothesis would prevail in our case. After carefully undertaken biological assays, the MIC values for this natural diterpene were very low to most microorganisms and could be stated as very promising, as they were lower than $10.0 \mu \mathrm{g} \mathrm{mL}^{-1} .36,39$ These values are also lower than some previously reported in the literature for other diterpenes, such as clerodanes,${ }^{40}$ isopimaranes ${ }^{41}$ and abietanes. ${ }^{42}$ With these results, we can state that Urzúa's hypothesis is confirmed so far.

In the second step, we evaluated another natural diterpene, also an acid diterpene, with only one HBD group, but with a different basic structure-being a caurane diterpene (1). In this case, results were also encouraging, despite the fact that they were not as promising as the obtained for compound 2. Considering that the microorganisms are multi-resistant bacteria, these are expressive results. One can also state that these results are also in agreement with Urzúa's hypothesis. ${ }^{38}$

For further investigations of the antimicrobial activity, our second work strand was to evaluate semi-synthetic derivatives from both natural diterpenes ( $\mathbf{1}$ and $\mathbf{2}$ ). As our concern was also to evaluate the scope of Urzúa's hypothesis during the seek for new active compounds, a very suitable reaction to apply was esterification. Once our diterpenes were acids, the production of esters would eliminate the hydrogen-bond donor (HBD) group without infringing major changes in the rest of the structure. A considerable variety of esters were produced with five different $R_{1}$ chains, as can be seen on Figures 2 and 3 . This variety was proposed to verify if, even though the products being esters, the activities would vary somehow. Nevertheless, there was also the interest to evaluate if some other structural features could influence activity. Therefore, hydrogenation and methoxy-group addition were also planned to this study.

Firstly, hydrogenated products from $\mathbf{1}$ and $\mathbf{2}$ were produced and are presented as compounds $\mathbf{8}$ and $\mathbf{2 5}$, respectively. Thereafter, compound $\mathbf{1 4}$ was prepared by methoxy-group addition in compound $\mathbf{1}$. Compound $\mathbf{2}$ did not undergo methoxy-group addition by the applied methodology. All three new structures $(\mathbf{8}, 14$ and 25) were used as precursors to produce esters together with compounds $\mathbf{1}$ and $\mathbf{2}$.

Biological assays of hydrogenated compounds revealed the most promising result in this work assigned

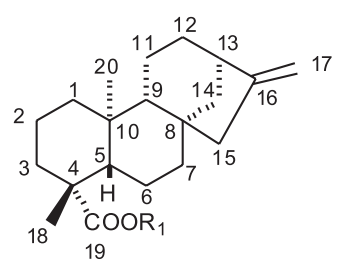

$$
\begin{aligned}
& \text { 1 }(\mathrm{KA}): \mathrm{R}_{1}=\mathrm{H} \\
& \text { 3: } \mathrm{R}_{1}=\left(\mathrm{CH}_{2}\right)_{3} \mathrm{CH}_{3} \\
& \text { 4: } \mathrm{R}_{1}=\mathrm{PhCH}_{2} \\
& \text { 5: } \mathrm{R}_{1}=4-\mathrm{CIPhCH}_{2} \\
& \text { 6: } \mathrm{R}_{1}=4-\mathrm{BrPhCH}_{2} \\
& \text { 7: } \mathrm{R}_{1}=\mathrm{CH}_{3}
\end{aligned}
$$

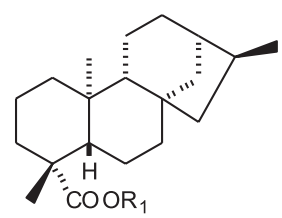

8: $\mathrm{R}_{1}=\mathrm{H}$

9: $\mathrm{R}_{1}=\left(\mathrm{CH}_{2}\right)_{3} \mathrm{CH}_{3}$

10: $\mathrm{R}_{1}=\mathrm{PhCH}_{2}$

11: $\mathrm{R}_{1}=4-\mathrm{CIPhCH}_{2}$

12: $\mathrm{R}_{1}=4-\mathrm{BrPhCH}_{2}$

13: $\mathrm{R}_{1}=\mathrm{CH}_{3}$

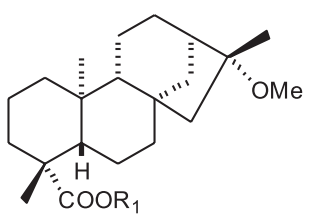

14: $\mathrm{R}_{1}=\mathrm{H}$

15: $\mathrm{R}_{1}=\left(\mathrm{CH}_{2}\right)_{3} \mathrm{CH}_{3}$

16: $\mathrm{R}_{1}=\mathrm{PhCH}_{2}$

17: $\mathrm{R}_{1}=4-\mathrm{CIPhCH}_{2}$

18: $\mathrm{R}_{1}=4-\mathrm{BrPhCH}_{2}$

19: $\mathrm{R}_{1}=\mathrm{CH}_{3}$

Figure 2. Chemical structure of ent-kaurenoic acid (1), from Mikania glomerata Spreng, and its semi-synthetic derivatives. 


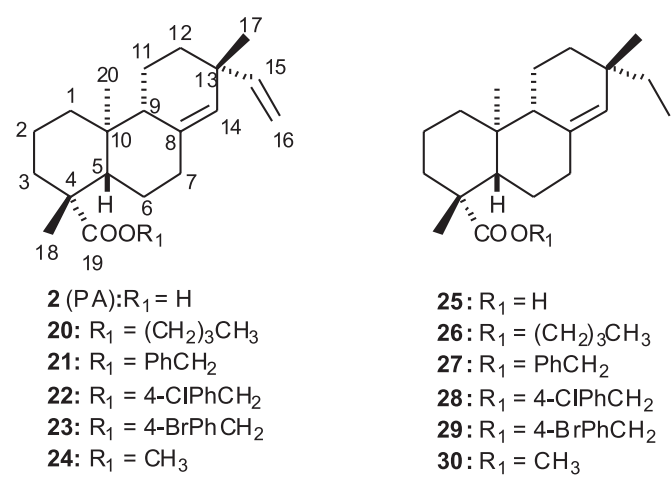

Figure 3. Chemical structures of ent-pimaradienoic acid (2), from Viguiera arenaria and its semi-synthetic derivatives.

to a semi-synthetic derivative. Compound 25 showed promising MIC values against four microorganisms. At first look, this result seems to be worse than the obtained for compound 2, its precursor, which displayed promising MIC values against six microorganisms. Nevertheless, a careful observation stands out that compound $\mathbf{2 5}$ performed better than compound $\mathbf{2}$ against the whole set of Staphylococcus aureus. Compound $\mathbf{2}$ is inactive against S. aureus (223 HCRP). Taking into account that $S$. aureus is one of the most relevant microorganisms concerning uncontrolled infectious diseases by multidrug resistant bacteria according to $\mathrm{WHO},{ }^{2}$ the activity of compound 25 is indeed a very promising result. On the other hand, compound $\mathbf{8}$, the other hydrogenated derivative, showed to be totally inactive. Likewise, compound $\mathbf{1 4}$, the methoxylated derivative from $\mathbf{1}$, also showed to be inactive, confirming that the only active derivative prepared through both reactions is compound $\mathbf{2 5}$.

The esters produced from the five precursors make up a set of $\mathbf{2 5}$ substances of two different basic diterpene skeletons with the variety of five different ester chains including two aliphatic (short and longer chain) and three aromatic (hydrocarbon, chlorinated and brominated) chains. Moreover, there are other structural differences as a consequence of hydrogenation and methoxylation. Unfortunately, it was verified that none of these structural variations were able to cause the expression of any activity in esters. This leads to two interesting conclusions, the first being that the results of this work showed to be in a remarkable agreement with Urzua's hypothesis. The only substances that showed results against this hypothesis were compounds 8 and 14; inactive compounds containing one HBD group. This could be considered as a $93 \%$ of agreement. The second conclusion is that the most relevant structural transformation applied that seems to influence the antimicrobial activity against these MDR bacteria is the hydrogenation. Nevertheless, this only worked with the pimarane skeleton.
Further investigations were carried out submitting the three most active compounds in this work to evaluate their toxicity. All results obtained are plotted on Table 2 .

No cytotoxic effect against primary human fibroblasts in vitro was detected at active concentrations for compound 25. In general, cytotoxicity of compound 25 was detected to be very similar to the cytotoxicity evaluated for the natural compounds $\mathbf{1}$ and $\mathbf{2}$. These very low cytotoxicity results allow further assays as in vivo mode and make the antimicrobial results even more expressive.

Table 2. Cytotoxicity evaluated for most active compounds

\begin{tabular}{lccc}
\hline & \multicolumn{3}{c}{ Cell viability / \% } \\
\cline { 2 - 4 } Assayed concentration & $\mathbf{1}$ & $\mathbf{2}$ & $\mathbf{2 5}$ \\
\hline $31.25 \mu \mathrm{g} \mathrm{mL}^{-1}$ & 97 & 83.7 & 80.2 \\
$15.6 \mu \mathrm{g} \mathrm{mL}^{-1}$ & 100 & 96.7 & 96.4 \\
$7.8 \mu \mathrm{g} \mathrm{mL}^{-1}$ & 100 & 100 & 100 \\
Positive control & 32.9 & 32.9 & 32.9 \\
Negative control & 100 & 100 & 100 \\
\hline
\end{tabular}

To investigate even further the antimicrobial potential of these diterpenes, time-kill curve assays were performed against $S$. aureus $180 \mathrm{HCRP}\left(3.6 \times 10^{5} \mathrm{CFU} \mathrm{mL}^{-1}\right)$ for compounds $\mathbf{1}, \mathbf{2}$ and $\mathbf{2 5}$, the most active substances. These curves were drawn using minimal bactericidal concentrations (MBC) results obtained for each substance and were plotted in Figure 4. MBC values for vancomycin and for compounds $\mathbf{1}$ and $\mathbf{2}$ were the same as their MIC values, stating that they are all bactericidal antimicrobial agents. On the other hand, compound 25 presents an MBC value much higher than its MIC value, which suggests a bacteriostatic antimicrobial action by this diterpene. The time-kill curve assays showed that compounds $\mathbf{1}$ and $\mathbf{2}$ were able to completely kill the tested $S$. aureus strain after only $12 \mathrm{~h}$ of incubation, which was half the time for the same effect from vancomycin. This can be considered a very expressive result, classifying compounds $\mathbf{1}$ and $\mathbf{2}$ as important structures to be used as new antimicrobial agents against MDR bacteria.

Meanwhile, compound $\mathbf{2 5}$ revealed to be able to completely kill the tested $S$. aureus strain after $24 \mathrm{~h}$ of incubation, just like the positive control, showing a curve profile very similar to the one displayed by vancomycin. However, this compound was assayed in a higher concentration, due to its bacteriostatic antimicrobial action.

Another interesting result that must be highlighted is that all assayed compounds caused drastic reductions in the number of microorganisms after $6 \mathrm{~h}$. Considering those results and taking into account the adverse effects 
associated with the use of several antibiotics and the increase of mortality of patients associated to the reduction in efficacy of drugs against MDR, compounds 1, 2 and 25 can be considered very relevant to the search for new antimicrobial agents.

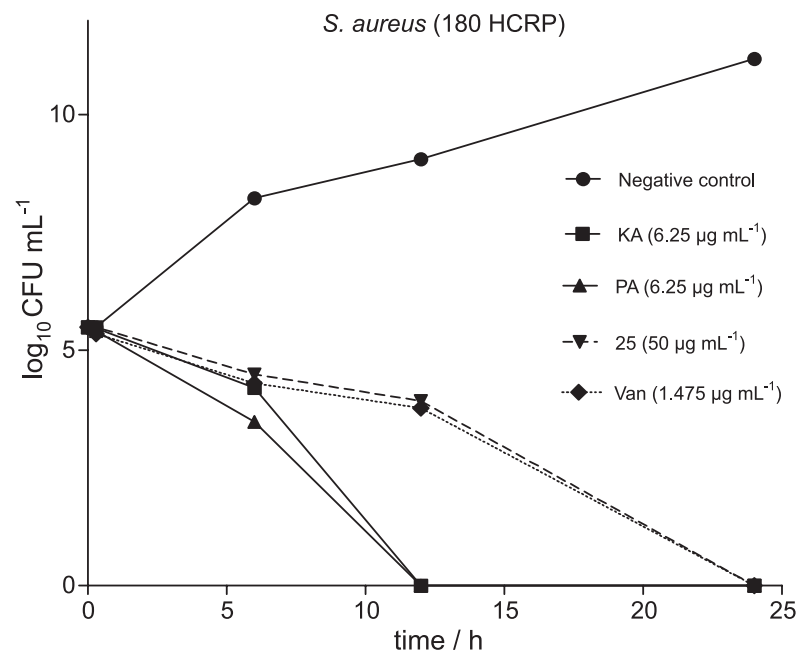

Figure 4. Time-kill curve profiles for KA (1), PA (2) and 25 against S. aureus. Positive control: VAN.

The structure-activity relation between diterpenes and their antimicrobial activity clearly depends on their nonpolar ring system, or their basic skeleton. This can be stated by comparison of pairs of diterpenes here studied, which differ only in this feature, such as $\mathbf{1}$ and $2 ; 8$ and $25 ; 3$ and 20; 9 and 26; 10 and 27; 11 and 28. In all pairs, without exception, pimaranes prevail. This is more evident and meaningful in the first two pairs. After that, as stated before, Urzúa's hypothesis also prevails, in $93 \%$ of our cases.

In this work, two natural diterpenes were found to be promising against MDR bacteria and, moreover, one semi-synthetic derivative was produced and can also be classified as promising.

In summary, our search yielded compound $\mathbf{1}$ and $\mathbf{2}$ as promising natural products against MDR bacteria, both by MIC values and for their performance in timekill curve assay, in the latter, better than vancomycin. It further provided a semi-synthetic derivative (25) also with promising MIC values against the bacteria set here studied and with time-kill curve profile resembling vancomycin acting. In special, compound $\mathbf{2 5}$ displayed the lower MIC values for the $S$. aureus set (180 HCRP; 222 HCRP; 223 HCRP). Moreover, due to the obtained MIC and MBC values for $\mathbf{1}, \mathbf{2}$ and $\mathbf{2 5}$, and also by their behavior during time-kill curve experiment, another interesting feature can be discussed. Compounds $\mathbf{1}$ and $\mathbf{2}$ clearly present bactericidal antimicrobial action, while $\mathbf{2 5}$ behaves as bacteriostatic antimicrobial agent. Despite the fact that this intuitively comprehensive concept induces the idea that bactericidal drugs have more powerful antibacterial action, Nemeth et al ${ }^{43}$ have proved that the categorization of antibiotics into bactericidal and bacteriostatic is unlikely to be relevant in clinical practice for several kinds of infection. In this study, it was verified that neither clinical cure rates nor overall mortality and nor results against microorganisms were significantly different for bactericidal or bacteriostatic drugs. Moreover, several classes of commercial antibiotics are bacteriostatic, such as macrolides and tetracyclines. ${ }^{44}$ Several of them present a broad action spectrum and high efficacy against aerobe and anaerobe bacteria, Gram-positive and Gram-negative, including some resistant to other antibiotics. ${ }^{44}$ This makes our results even more interesting.

Lastly, these results for $\mathbf{2 5}$ highlight the relevance of structural modifications in natural products in the search for promising biological active compounds.

\section{Conclusions}

The biological assays performed during this work allowed us to know the promising antimicrobial potential against multi-resistant bacteria of two natural diterpenes, named ent-pimeradienoic acid and ent-kaurenoic acid. Moreover, this work allowed the production of a semi-synthetic diterpene derivative even more efficient as antimicrobial agent against multi-resistant Staphylococcus aureus. Beyond that, several esters derivatives were produced to enable a better comprehension of structure-activity relationship of antimicrobial diterpenes.

\section{Supplementary Information}

Supplementary information, containing ${ }^{1} \mathrm{H}$ and ${ }^{13} \mathrm{C}$ NMR spectral data for all compounds in this work, is available free of charge at http://jbcs.sbq.org.br as PDF file.

\section{Acknowledgments}

The authors wish to thank FAPESP-Fundação de Amparo à Pesquisa do Estado de São Paulo for funds and grants (No. 2011/07885-2 and 2009/09491-1).

\section{References}

1. Schito, A. M.; Piatti, G.; Stauder, M.; Bisio, A.; Giacomelli, E.; Romussi, G.; Pruzzo, C.; Int. J. Antimicrob. Agents 2011, 37, 129.

2. World Health Organization, Antimicrobial Resistance Global Report on Surveillance, available at http://apps.who.int/iris/ 
bitstream/10665/112642/1/9789241564748_eng.pdf?ua=1, accessed on May 13, 2018.

3. World Health Organization, Antibiotic Resistance, available at http://www.who.int/mediacentre/factsheets/antibioticresistance/en/, accessed on May 13, 2018.

4. Reda, F. M.; Shafi, S. A.; Ismail, M.; Appl. Biochem. Microbiol. 2016, 52, 593.

5. World Health Organization, Global Action Plan on Antimicrobial Resistance, available at http://www.who.int/drugresistance/ global_action_plan/en/, accessed on May 13, 2018.

6. Czekaj, T.; Ciszewski, M.; Szewczyk, E. M.; Microbiology 2015, 161, 2061.

7. Rasigade, J. P.; Raulin, O.; Picaud, J. C.; Tellini, C.; Bes, M.; Grando, J.; Said, M. B.; Claris, O.; Etienne, J.; Tigaud, S.; Laurent, F.; PLoS One 2012, 7, e31548.

8. Black, R. E.; Cousens, S.; Johnson, H. L.; Lawn, J. E.; Rudan, I.; Bassani, D. G.; Jha, P.; Campbell, H.; Walker, C. F.; Cibulskis, R.; Eisele, T.; Liu, L.; Mathers, C.; Lancet 2010, 375, 1969.

9. Cantón, R.; Ruiz-Garbajosa, P.; Enferm. Infecc. Microbiol. Clin. 2013, 31, 543.

10. Reynolds, C. A.; Finkelstein, J. A.; Ray, G. T.; Moore, M. R.; Huang, S. S.; Antimicrob. Resist. Infect. Control 2014, 3, article 16.

11. Newman, D. J.; Cragg, G. M.; J. Nat. Prod. 2016, 79, 629.

12. de Luca, V.; Salim, V.; Atsumi, S. M.; Yu, F.; Science 2012, 336, 1658.

13. Porto, T. S.; Simão, M. R.; Carlos, L. Z.; Martins, C. H. G.; Furtado, N. A. J. C.; Said, S.; Arakawa, N. S.; dos Santos, R. A.; Veneziani, R. C. S.; Ambrosio, S. R.; Phytother. Res. 2013, 27, 1502.

14. Miron-Lopez, G.; Bazzocchi, I. L.; Jimenez-Diaz, I. A.; Moujir, L. M.; Quijano-Quiñones, R.; Quijano, L.; Mena-Rejon, G. J.; Bioorg. Med. Chem. Lett. 2014, 24, 2105.

15. Bou, D. D.; Tempone, A. G.; Pinto, E. G.; Lago, J. H.; Sartorelli, P.; Phytomedicine 2014, 21, 676.

16. Pardo-Vargas, A.; Ramos, F. A.; Cirne-Santos, C. C.; Stephens, P. R.; Paixão, I. C. P.; Teixeira, V. L.; Castellanos, L.; Bioorg. Med. Chem. Lett. 2014, 24, 4381.

17. Jiang, K.; Chen, L. L.; Wang, S. F.; Wang, Y.; Li, Y.; Gao, K.; J. Nat. Prod. 2015, 78, 1037.

18. Vargas, F. S.; de Almeida, P. D. O.; Aranha, E. S.; Boleti, A. P. A.; Newton, P.; de Vasconcellos, M. C.; Júnior, V. F.; Lima, E. S.; Molecules 2015, 20, 6194.

19. Miranda, M. M.; Panis, C.; da Silva, S. S.; Mediat. Inflamm. 2015, 2015, article ID 392918.

20. Win, N. N.; Ito, T.; Aimaiti, S.; Kodama, T.; Imagawa, H.; Ngwe, H.; Asakawa, Y.; Abe, I.; Morita, H.; Tetrahedron 2015, $71,4707$.

21. Andrade, B. B.; Moreira, M. R.; Ambrosio, S. R.; Furtado, N. A. J. C.; Cunha, W. R.; Heleno, V. C. G.; Silva, A. N.; Simão, M. R.; da Rocha, E. M.; Martins, C. H. G.; Veneziani, R. C. S.; Nat. Prod. Commun. 2011, 6, 777.
22. Batista, R.; García, P. A.; Castro, M. A.; del Corral, J. M. M.; Speziali, N. L.; Varotti, F. P.; de Paula, R. C.; García-Fernández, L. F.; Francesch, A.; San Feliciano, A.; de Oliveira, A. B.; Eur. J. Med. Chem. 2013, 62, 168.

23. Matos, P. M.; Mahoney, B.; Chan, Y.; Day, D. P.; Cabral, M. M. W.; Martins, C. H. G.; Santos, R. A.; Bastos, J. K.; Page, P. C. B.; Heleno, V. C. G.; Molecules 2015, 20, 18264.

24. Silva, A. N.; Soares, A. C. F.; Cabral, M. M. W.; Andrade, A. R. P.; Silva, M. B. M.; Martins, C. H. G.; Veneziani, R. C. S.; Ambrosio, S. R.; Bastos, J. K.; Heleno, V. C. G.; J. Braz. Chem. Soc. 2017, 28, 1106.

25. Sass, D. C.; Heleno, V. C. G.; Morais, G. O.; Lopes, J. L.; Lopes, N. P.; Constantino, M. G.; Org. Biomol. Chem. 2011, 9, 6148.

26. Carvalho, T. C.; Simão, M. R.; Ambrosio, S. R.; Furtado, N. A. J. C.; Veneziani, R. C. S.; Heleno, V. C. G.; da Costa, F. B.; Gomes, B. P.; Souza, M. G.; dos Reis, E. B.; Martins, C. H. G.; Molecules 2011, 16, 543.

27. Mota, S. F.; Oliveira, D. F.; Heleno, V. C. G.; Soares, A. C. F.; Midiwo, J. O.; Souza, E. A.; J. Agric. Food Chem. 2017, 65, 1489.

28. Boeck, P.; Sá, M. M.; de Souza, B. S.; Cercená, R.; Escalante, A. M.; Zachino, S. A.; Cechinel Filho, V.; Yunes, R. A.; J. Braz. Chem. Soc. 2005, 16, 1360.

29. Clinical and Laboratory Standards Institute (CLSI), Methods for Dilution Antimicrobial Susceptibility Tests for Bacteria that Grow Aerobically, $7^{\text {th }}$ ed.; Wayne: New York, 2006.

30. Sarker, S. D.; Nahar, L.; Kumarasamy, Y.; Methods 2007, 42, 321.

31. Porto, T. S.; Furtado, N. A.; Heleno, V. C. G.; Martins, C. H.; da Costa, F. B.; Severiano, M. E.; Silva, A. N.; Veneziani, R. C. S.; Ambrosio, S. R.; Fitoterapia 2009, 80, 436.

32. Gibbons, S.; Nat. Prod. Rep. 2004, 21, 263.

33. D’Arrigo, M.; Ginestra, G.; Mandalari, G.; Furneri, P. M.; Bisignano, G.; Phytomedicine 2010, 17, 317.

34. Tincusi, B. M.; Jiménez, I. A.; Bazzocchi, I. L.; Moujir, L.; Mamani, Z.; Barroso, J.; Ravelo, A.; Hernandez, B.; Planta Med. 2002, 68, 808.

35. Kumata, H.; Mori, M.; Takahashi, S.; Takamiya, S.; Tsuzuki, M.; Uchida, T.; Fujiwara, K.; Environ. Sci. Technol. 2011, 45, 9990.

36. Ríos, J. L.; Récio, M. C.; J. Ethnopharmacol. 2005, 100, 80.

37. Greenberg, M.; Dodds, M.; Tian, M.; J. Agric. Food Chem. 2008, 56, 11151.

38. Urzúa, A.; Rezende, M. C.; Mascayano, C.; Vásquez, L.; Molecules 2008, 13, 882.

39. Gibbons, S.; Planta Med. 2008, 74, 594.

40. Bisio, A.; Schito, A. M.; Parricchi, A.; Mele, G.; Romussi, G.; Malafronte, N.; Oliva, P.; de Tommasi, N.; Phytochem. Lett. 2015, 14, 170.

41. Siridechakorn, I.; Cheenpracha, S.; Ritthiwigrom, T.; Phakhodee, W.; Deachathai, S.; Machan, T.; Ruankeaw, N.; Laphookhieo, S.; Phytochem. Lett. 2014, 7, 186. 
42. Rijo, P.; Duarte, A.; Francisco, A. P.; Semedo-Lemsaddek, T.; Simões, M. F.; Phytother. Res. 2014, 28, 76.

43. Nemeth, J.; Oesch, G.; Kuster, S. P.; J. Antimicrob. Chemother. 2014, 70, 382 .
44. Guimarães, D. O.; Momesso, L. S.; Pupo, M. T.; Quim. Nova 2010, 33, 667 .
Submitted: June 17, 2018

Published online: September 18, 2018

(cc) BY This is an open-access article distributed under the terms of the Creative Commons Attribution License. 